\title{
Application of Earth Pigments in Cycloolefin Copolymer: Protection against Combustion and Accelerated Aging in the Full Sunlight Spectrum
}

\author{
Bolesław Szadkowski ${ }^{1}$, Małgorzata Kuśmierek ${ }^{1}$, Przemysław Rybiński ${ }^{2}$, \\ Witold Żukowski ${ }^{3}{ }^{-1}$ and Anna Marzec ${ }^{1, *}$ \\ 1 Institute of Polymer and Dye Technology, Faculty of Chemistry, Lodz University of Technology, \\ Stefanowskiego 12/16, 90-924 Lodz, Poland; boleslaw.szadkowski@dokt.p.lodz.pl (B.S.); \\ malgorzata.kusmierek@dokt.p.lodz.pl (M.K.) \\ 2 Institute of Chemistry, the Jan Kochanowski University, Żeromskiego 5, 25-369 Kielce, Poland; \\ przemyslaw.rybinski@ujk.edu.pl \\ 3 Department of Chemical Engineering and Technology, Cracow University of Technology, \\ 31-155 Kraków, Poland; witold.zukowski@pk.edu.pl \\ * Correspondence: anna.marzec@p.lodz.pl
}

Received: 10 June 2020; Accepted: 22 July 2020; Published: 30 July 2020

\begin{abstract}
In this paper, we assess various natural earth pigments as potential colorants and stabilizers for ethylene-norbornene copolymer composites. Several cycloolefin copolymer (COC) composites colored with $2 \mathrm{wt} \%$ of a selected pigment were prepared using a two-step mixing method. The aging resistance of the polymer composites was investigated in terms of changes to their mechanical properties, following accelerated aging in the full sunlight spectrum $(100,200,300$, 400, and 500 h). Fourier-transform infrared spectroscopy (FTIR), surface energy measurements, and spectrophotometry were used to assess the color changes, surface defects, and morphology of the composites. Thermogravimetric analysis (TGA) was used to study their thermal stability. The combustion characteristics of the prepared COC composites were evaluated based on the microcombustion calorimetry test (MCC). The application of earth pigments resulted in interesting color changes and a significant improvement in the aging resistance of the COC-filled samples, as evidenced by higher aging factor values and lower carbonyl index parameters compared to the reference (COC). The best results were observed for hematite (HM), gold ochre (GO), and red ochre (RO). In addition, the application of earth pigments, especially iron ochre (IO) and red ochre (RO), in COC contributed to a significant reduction in the heat release rate (HRR) values, indicating improved flame retardancy. This research opens the possibility of producing colorful COC composites with enhanced photostability and reduced flammability for use in polymer applications.
\end{abstract}

Keywords: earth pigments; ochres; ethylene-norbornene copolymer; light stability; accelerated aging; flammability

\section{Introduction}

Dyes and pigments are widely employed in various industrial and commercial applications, such as paints, construction materials, paper, ceramics, textiles, and plastics [1,2]. Pigments are colorants that have been incorporated into a polymer composite, via a dispersion process which forms a separate phase in the dyed material. Pigments have a limited tendency to migrate and are practically insoluble in most media, which is important from a practical point of view. Pigments are conventionally classified as either inorganic or organic. Organic pigments are in general characterized by high brightness and good color strength. However, they offer different fastness properties (low thermo- 
and photostability) [3]. Organic pigments require a lengthy synthesis process, often in the presence of harmful solvents, which is a disadvantage from both the ecological and economical points of view. There is therefore great interest in finding potential substitutes for organic pigments currently used in many areas of industry.

Recent studies have presented hybrid pigments with improved applicative properties, prepared by modifying inorganic carriers with organic dyes [4-7]. Another alternative is the application of inorganic pigments as colorants. The advantage of inorganic pigments is that they are produced via relatively simple chemical reactions (particularly oxidation) or found naturally as earths. Earth pigments are inorganic, naturally-occurring materials of mineral origin. They have been used as coloring substances for thousands of years, due to their widespread availability, strong coverage, durability, and color stability [8].

Iron oxides are a large group of pigments, including earth pigments, ochres, and iron ores. They are distinguished based on their color, for instance as yellow ochres, red ochres, and umbers. This may be a non-clay pigment, such as an iron oxide, or a chromogenous element in the clay structure [9]. Recently, earth pigments have attracted much interest, due to their intense color, low cost, facile application, and versatile properties [10-14]. They have found many applications, including as catalysts and drug carriers, in magnets and plastics, as well as for wastewater treatment and adsorption processes.

Many plastic products are used outdoors, so it is of great importance to study their chemical and physical behavior in outdoor environments. Photodegradation is known to cause serious alterations in the physical performance of materials, such as surface yellowing, cracking, embrittlement, and stiffening of the polymer composite $[15,16]$. Based on the literature on pigments in polymer systems, pigment colorants that absorb UV light could provide a shielding effect against photodegradation [17-19]. Iron ores (including earth pigments) can be used as additives in composite materials, to improve their functional properties. Camlibel et al. [14] showed that the incorporation of iron ores as additives in cotton fabrics coated with polyacrylate polymer improved their flame retardant and antibacterial properties, while also providing UV protection and coloration. Haug et al. [20] and Kiat-amnuay et al. [21] reported that the application of dry earth pigments can protect silicone rubber composites against weathering. Other research shows that hematite pigment improves thermal stability and reinforces the mechanical performance of polymer composites [22,23].

When selecting colorants for polymer blends, it is necessary to know the effect of the additive on both the polymer stability and its other applicative properties. The physico-chemical performance of earth pigments, such as high thermal stability and chemical resistance, as well as their natural origin, make them interesting colorants in polymer materials. There is little in the literature regarding the stabilization of polymer composites against long-term light exposure using earth pigments such as golden, iron or red ochre. Moreover, the wide variety of earth pigments and their complex chemical constitution may affect the polymer degradation process in different ways. The potential use of earth pigments as stabilizers for cycloolefin copolymers (COC) has never been discussed. These copolymers were first produced in the late 1950s but only became available on the market relatively recently. One of the most important is ethylene-norbornene copolymer, which is known for its high purity, glass-like transparency, and low permeability to gas and water. Due to these properties, ethylene-norbornene copolymer is widely used in packaging [24,25]. However, products made from COC exhibit significant photodegradation and thermal oxidation when exposed to outdoor conditions, resulting in alterations to their surface characteristics and deterioration of their mechanical properties. This currently precludes the long-term use of materials made from COC in outdoor environments.

In our previous work, we studied the stabilizing effects of organic-inorganic pigments based on magnesium-aluminum hydroxycarbonates and organic dyes on COC polymers under UV irradiation and aging in the full sun spectrum [26,27]. In the present study, we investigated the application of earth pigments as natural multicolor stabilizers for ethylene-norbornene copolymer. Earth pigments of different colors and compositions were applied as additives in the COC copolymer at $2 \%$ concentration. The resulting colorful composites were subjected to prolonged irradiation in the full sunlight spectrum. 
Alterations in their surface and color characteristics were assessed, as well as mechanical performance. Their effect on the flammability of the COC composites was also evaluated.

\section{Materials and Methods}

\subsection{Materials}

Six earth pigments of different colors were selected for this study (the pigments were in powder form and the size of the pigments was in range of 1-50 $\mu \mathrm{m}$ ). The names, abbreviations, suppliers, and chemical compositions of the samples are listed in Table 1. Ethylene-norbornene random copolymer (ELASTOMER E-140) with $40 \mathrm{wt} \%$ bound norbornene content was purchased from IMCD Polska Sp. z o. o. (Warszawa, Poland) and employed as a polymer matrix. Diiodomethane and ethylene glycol were supplied by Sigma Aldrich (St. Louis, MO, USA). All chemicals were used as received, without further purification.

Table 1. Description of earth pigments applied in the study.

\begin{tabular}{|c|c|c|c|}
\hline Name & Abbreviation & Supplier & Chemical Composition \\
\hline Hematite * & $\mathrm{HM}$ & Kremer Pigments & $\mathrm{Fe}_{2} \mathrm{O}_{3}$ \\
\hline Gold ochre * & $\mathrm{GO}$ & Kremer Pigments & $\mathrm{Fe}_{2} \mathrm{O}_{3}, \mathrm{SiO}_{2}, \mathrm{Al}_{2} \mathrm{O}_{3}, \mathrm{CaCO}_{3}$ \\
\hline Iron ochre * & $\mathrm{IO}$ & Kremer Pigments & $\mathrm{Fe}_{2} \mathrm{O}_{3} \cdot \mathrm{H}_{2} \mathrm{O}, \mathrm{Fe}_{2} \mathrm{O}_{3}, \mathrm{Al}_{2} \mathrm{O}_{3}, \mathrm{CaCO}_{3}, \mathrm{SiO}_{4}$ \\
\hline Red ochre * & $\mathrm{RO}$ & Kremer Pigments & $\mathrm{Fe}_{2} \mathrm{O}_{3}, \mathrm{SiO}_{2}, \mathrm{Al}_{2} \mathrm{O}_{3}$ \\
\hline Brown ochre * & $\mathrm{BO}$ & Kremer Pigments & $\mathrm{Fe}_{2} \mathrm{O}_{3}, \mathrm{Al}_{2} \mathrm{O}_{3}, \mathrm{Mn}_{2} \mathrm{O}_{3}, \mathrm{SiO}_{4}, \mathrm{CaCO}_{3}$ \\
\hline Puzzola & PU & Kremer Pigments & $\begin{array}{l}\text { Mix of red earths containing } \mathrm{Sb}, \mathrm{As}, \mathrm{Ba}, \mathrm{Be}, \mathrm{Pb}, \mathrm{Cd} \\
\mathrm{Cr}, \mathrm{Co}, \mathrm{Cu}, \mathrm{Mn}, \mathrm{Ni}, \mathrm{Os}, \mathrm{Hg}, \mathrm{Se}, \mathrm{Au}, \mathrm{Tl}, \mathrm{V}, \mathrm{Sn}, \mathrm{Zn} .\end{array}$ \\
\hline
\end{tabular}

\subsection{Experimental Methods}

The compounding process was carried out on an internal Brabender Measuring Mixer N50 (Duisburg, Germany). The COC compounds contained $100 \mathrm{phr}$ (parts per hundred part of rubber) of ethylene-norbornene copolymer and $2 \mathrm{phr}$ of earth pigment. The ethylene-norbornene compositions were processed at a rotor speed of $50 \mathrm{rpm}$ at an initial temperature of $110^{\circ} \mathrm{C}$ for a mixing time of $10 \mathrm{~min}$. Subsequently, the as-obtained COC compounds were mixed in a laboratory-scale open two-roll mixing mill. Polymer films with a thickness of $1.0 \pm 0.1 \mathrm{~mm}$ were obtained by pressing the COC-filled compounds between two hot steel plates for $5 \mathrm{~min}$ at $110^{\circ} \mathrm{C}$ and $6 \mathrm{MPa}$.

The resistance of the COC composites to photodegradation was determined on a Solar Climatic 340 instrument. Accelerated ageing was performed in a wavelength $(\lambda)$ range of $280-3000 \mathrm{~nm}$ over $500 \mathrm{~h}$, with light radiation intensity of $1200 \mathrm{~W} / \mathrm{m}^{2}$ (luminous flux $110,000 \mathrm{~lm}$ ). The polymer samples were mounted in specimen holders, so that their entire surface was exposed to light radiation. The weathering procedure consisted of two alternately repeating segments: day (solar irradiation, $70{ }^{\circ} \mathrm{C}$, humidity $50 \%$, $8 \mathrm{~h}$ ) and night $\left(20^{\circ} \mathrm{C}\right.$, humidity $\left.60 \%, 4 \mathrm{~h}\right)$. The color, surface, and mechanical properties of the prepared composites were characterized following the weathering process.

A Minolta CM-2500d spectrophotometer (Konika Minolta Sensing Inc., Osaka, Japan) was used to measure the color of the treated and untreated COC composites, in a spectral range from 360 to $740 \mathrm{~nm}$. The CIE L $\cdot \mathrm{a} \cdot \mathrm{b}$ color space system was employed to determine the surface color of the samples. The total color change parameter $(\Delta \mathrm{E})$ was calculated as outlined in ISO 7724, according to the following equation:

$$
\Delta E=\sqrt{\Delta L^{2}+\Delta a^{2}+\Delta b^{2}},
$$

where $\Delta \mathrm{L}, \Delta \mathrm{a}$, and $\Delta \mathrm{b}$ represent the differences between the initial and final values of $\mathrm{L}$ (brightness), a (red-green color coordinate), and b (yellow-blue color coordinate), respectively. 
The reflectance of the colored COC composites was recorded on an Evolution 201/220 UV-Visible Spectrophotometer (Thermo Fisher Scientific, Waltham, MA, USA). The measurements were performed for composite specimens that were placed in a special cell holder with a spectral window from 1100 to $200 \mathrm{~nm}$ at room temperature. Before the experiments, the baseline was corrected using a special calibration adapter. The accuracy of the apparatus was $\pm 0.8 \mathrm{~nm}$ and the repeatability was $\leq 0.05 \mathrm{~nm}$.

The mechanical performance of the samples before and after the aging process were evaluated based on tensile tests, using a Zwick 1435 tensile testing machine (Zwick Roell Group, Ulm, Germany) in accordance with the ISO-37 standard. The mechanical parameters were evaluated in the presence of the extensometer and the tensile strength value was determined from the equation:

$$
\mathrm{T}_{\mathrm{S}}=\mathrm{F} / \mathrm{W} \cdot \mathrm{t},
$$

where $\mathrm{F}$ is the force registered at break $(\mathrm{N}), \mathrm{W}$ is the width of the narrowed part of the sample $(\mathrm{mm})$, and $t$ is the sample thickness ( $\mathrm{mm}$ ).

The measurements were carried out on dumbbell-shaped specimens at room temperature, with a crosshead speed of $500 \mathrm{~mm} / \mathrm{min}$. Five individual samples of each tested composite were used. Based on the results, the aging coefficient was calculated using the following formula [28]:

$$
\text { Aging factor }=\left(\mathrm{T}_{\mathrm{S}} \cdot \mathrm{E}_{\mathrm{B}}\right)_{\mathrm{after} \text { aging }} /\left(\mathrm{T}_{\mathrm{S}} \cdot \mathrm{E}_{\mathrm{B}}\right)_{\text {before aging, }}
$$

where $\mathrm{T}_{\mathrm{S}}$ and $\mathrm{E}_{\mathrm{B}}$ are the tensile strength (MPa) and elongation at break (\%) of the COC composites.

The surface characteristics of the studied COC samples were examined using an OEC 15EC goniometer (DataPhysics Instruments $\mathrm{GmbH}$, Germany). Surface free energy was determined based on the Owens, Wendt, Rabel, and Kaelble (OWRK) method [29]. The polar and disperse parts of the surface energy are described by the equations:

$$
\sigma_{1}=\sigma_{1}^{\mathrm{d}}+\sigma_{\mathrm{l}}^{\mathrm{p}}
$$

and

$$
\sigma_{\mathrm{s}}=\sigma_{\mathrm{s}}^{\mathrm{d}}+\sigma_{\mathrm{s}}^{\mathrm{p}}
$$

where $\sigma_{1}{ }^{d}$ and $\sigma_{1}{ }^{p}$ represent the disperse and polar parts of the liquid, while $\sigma_{s}{ }^{d}$ and $\sigma_{s}{ }^{p}$ represent the disperse and polar parts of the solid. The interfacial surface energy of the materials can be calculated according to OWRK from the contributions of the liquid and the solid, by finding the geometric mean and using the equations:

$$
y=a x+b
$$

and

$$
y=\frac{\left(1+\cos \frac{\theta}{2}\right) \cdot \sigma_{l}}{\sqrt{\sigma_{l}^{d}}} ; x=\sqrt{\frac{\sigma_{l}^{p}}{\sigma_{l}^{d}}} ; a=\sqrt{\sigma_{s}^{p}} ; b=\sqrt{\sigma_{s}^{d}},
$$

To determine the contact angle value $(\theta)$, the following liquids with different polarities were employed: diiodomethane, ethylene glycol, and distilled water.

Fourier transform infrared (FTIR) spectroscopy was performed on the COC samples before and after weathering using a Thermo Scientific Nicolet 6700 FTIR spectrometer (Thermo Scientific, Waltham, MA, USA). The FTIR spectra for all the samples were recorded with 32 scans at $4 \mathrm{~cm}^{-1}$ resolution in a scanning range from 400 to $4000 \mathrm{~cm}^{-1}$. The carbonyl index (CI) was determined using the following equation [30]:

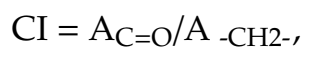

where $A_{C=O}$ refers to the area of the carbonyl absorption band in the range of $1800-1680 \mathrm{~cm}^{-1}$ and $\mathrm{A}_{(-\mathrm{CH} 2-)}$ is the area of the internal reference band in the range of $3000-2800 \mathrm{~cm}^{-1}$ corresponding 
to asymmetric stretching vibrations in methylene groups (this peak remains unchanged during photodegradation).

Thermogravimetric Analysis (TGA) in two different atmospheres was applied to monitor the thermal degradation process, which is related to mass loss as a function of rising temperature. A TA Instruments Q500 Thermogravimetric Analyzer (Mettler Toledo, Greifensee, Switzerland) was used with a heating rate of $10^{\circ} \mathrm{C} / \mathrm{min}$, under argon (flow rate of $60 \mathrm{~mL} / \mathrm{min}$ ) and air (flow rate of $20 \mathrm{~mL} / \mathrm{min}$ ) atmospheres. Thermal stability tests were performed for samples with $10 \mathrm{mg}$ mass in a temperature range of $25-600{ }^{\circ} \mathrm{C}$.

Microscale combustion calorimetry was employed to determine the flammability of the composites filled with earth pigments. For this purpose, similar fragments of each composites weighing approximately $2.5 \mathrm{mg}$ were analyzed on an MCC micro-calorimeter (Fire Testing Technology Limited). Flammability measurements were performed with the following parameters: pyrolyzer temperature $750{ }^{\circ} \mathrm{C}$, combustor temperature $900^{\circ} \mathrm{C}$.

The morphology of the earth pigments and COC composites was assessed based on scanning electron microscopy (SEM). Microphotographs of the samples were obtained using a LEO1530 Gemini scanning electron microscope (Zeiss/Leo, Oberkochen, Germany). Prior to the SEM measurements, the composite samples were immersed in liquid nitrogen and the location of the fracture was covered with a carbon layer.

\section{Results}

\subsection{Photostability}

The degradation of polymer composites due to solar irradiation is a serious issue, resulting in numerous material failures, such as reductions in mechanical performance and deterioration of surface quality (yellowing and cracks). The resistance of a polymer to solar light is one of the main factors that determine the lifetime of the final polymeric product. The application of pigments with the ability to absorb and/or screen out UV light can therefore have a marked protective effect. At the same time, some dyes and pigments have a negative effect on the degradation and oxidation of polymers, accelerating the degradation process. Therefore, it is important to study how the origin, structure, and chemical composition of pigments can influence the photostability of polymers.

The COC composites colored with various earth pigments were exposed to accelerated and prolonged solar aging. Their color, surface characteristics, and mechanical performance were monitored. Surface discoloration was represented by the total color change parameter $(\Delta \mathrm{E})$ registered after exposure of the samples to solar irradiation (Figure 1 and Table A1).

As would be expected, due to its transparency, the neat COC copolymer showed a negligible color change even after $500 \mathrm{~h}$ of aging. However, in most cases, there was only a slight increase in $\Delta \mathrm{E}$ following exposure of the COC composites containing earth pigments to solar irradiation. Some slight discoloration was observed for COC/HM, COC/IO, and COC/PU after $300 \mathrm{~h}$, while the surface color of the COC/GO and COC/RO composites remained unchanged even after $500 \mathrm{~h}$ of aging. Therefore, it can be concluded that the best protection against sunlight was provided by gold and red ochres.

The opposite effect was observed for brown ochre. The COC/BO composite showed a rapid change in $\triangle \mathrm{E}$ after $300 \mathrm{~h}$ of aging. This difference indicates that the $\mathrm{COC} / \mathrm{BO}$ composite faded much more than the other samples, probably due to the lower stability of the brown ochre pigment under the applied aging conditions. The solar heat energy generated in the NIR region (700-1100 nm) created heat waves, which contribute to the build-up of heat in the polymer and may result in faster degradation of this materials. Moreover, ultraviolet rays (UVA 400-320 nm and UVB 320-290 nm) cause a photochemical effect within the polymer structure which affects its stability. According to the literature, both organic and inorganic pigments generally improve the light stability of polymeric materials [31,32]. The positive impact of pigments on the light stability of polymer is most likely due to their screening or selective absorption of harmful radiation, and to the deactivation of polymer photoexcited species. 
However, several colorants are photoactive and can therefore catalyze and accelerate the photochemical breakdown of the polymer. Based on current knowledge, it is difficult to predict the extent to which a pigment will have a protective effect.

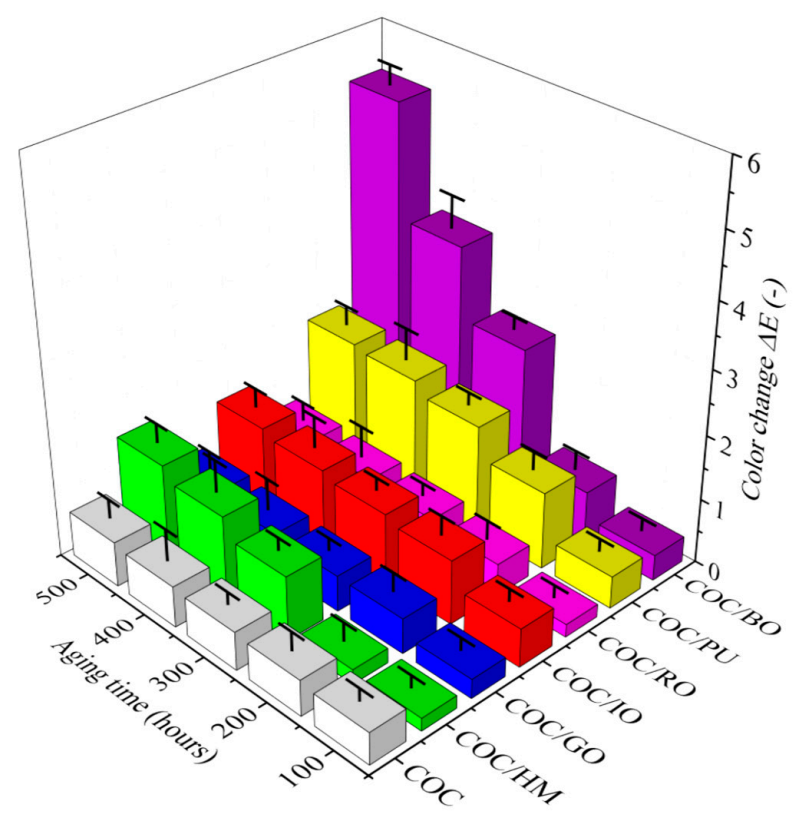

Figure 1. Color change parameter $(\Delta \mathrm{E})$ for the studied composites at different aging times.

The optical properties of the earth pigments were investigated using UV/Vis spectroscopy in the range of 200-1200 nm. Colored pigments have very different absorbance spectra, depending on the specific interaction of visible light with the valence electrons of the colorants. The yellow pigments (golen ochre and iron ochre) exhibited absorbance in range 200-400 nm, red COC composites (hematite, puzzola, and red ochre) were characterized by absorbance in higher values of wavelengths $300-600 \mathrm{~nm}$, and sample with brown pigment showed wide, blurry peak in the UV and visible regions. Interestingly, NIR-reflectance values varied for particular pigments (Figure 2). The spectral results revealed the presence of brown ochre as colorant provide reflectance in NIR region lower than $10 \%$. Therefore, it can be suspected that poor stability of $\mathrm{COC} / \mathrm{BO}$ sample may be resulted from chemical nature of this pigment i.e., ability to absorption/reflection of light and its photoactivity in the studied irradiation condition [33].

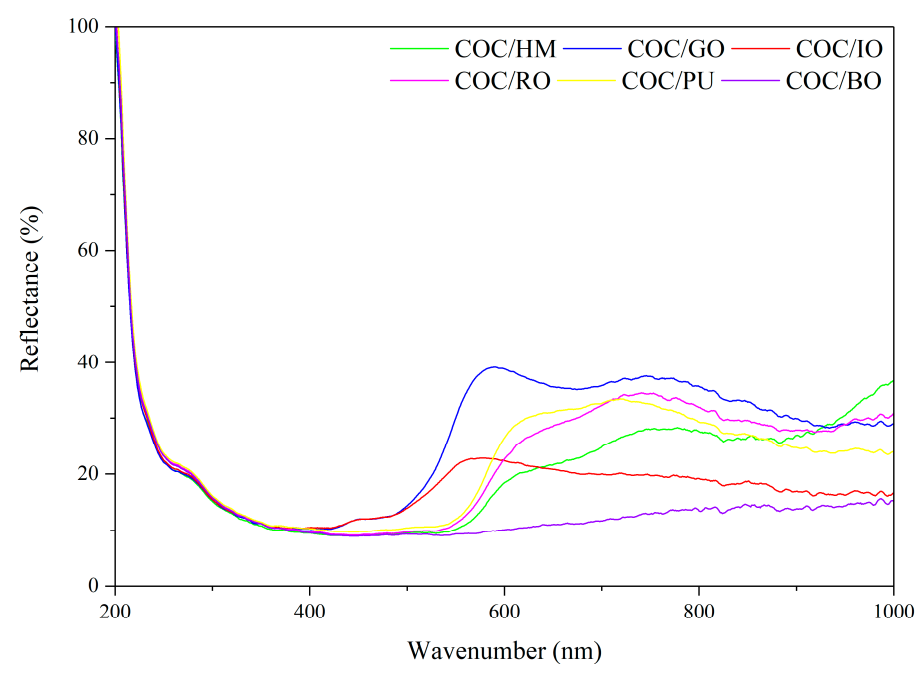

Figure 2. Light reflectance of the COC composites filled with different earth pigments. 
The relatively small color changes in the COC composites filled with other earth pigments may be explained by the protective activity of the pigments in the polymer matrix, which physically block solar irradiation [34,35]. It is well-documented that iron oxides, which are also considered to be earth pigments, exhibit the ability to absorb light in a wide spectrum $(200-800 \mathrm{~nm})$ [36]. This may be the main reason earth pigments effectively protected the polymer composite surface against the negative effects of solar irradiation. In other words, under accelerated aging conditions, solar light may enter and damage unprotected COC materials; however, the application of earth pigments can prevent solar irradiation from photodegrading COC macromolecules, due to their absorption/reflection of damaging light radiation in the UV and NIR regions.

The photodegradation progress was further examined using FTIR spectroscopy. Structural changes caused by exposure to solar irradiation were observed by monitoring the absorbance of the carbonyl groups (1600-1800 $\mathrm{cm}^{-1}$ ) on the FTIR spectra. The FTIR spectra of the COC composites show several characteristic peaks, such as 2915 and $2847 \mathrm{~cm}^{-1}$, which can be attributed to the stretching vibration of $\mathrm{CH}_{2} ; 1462 \mathrm{~cm}^{-1}$, which is related to the stretching vibration of C-O-C; and $718 \mathrm{~cm}^{-1}$, which can be assigned to $\mathrm{CH}_{2}$ rocking vibration (Figure 3). The most interesting result was observed at $1712 \mathrm{~cm}^{-1}$, which is attributed to the carbonyl groups $(\mathrm{C}=\mathrm{O})$. Neat $\mathrm{COC}$ exhibited a significant increase in this peak after aging, compared to the COC/RO sample. The CI parameters for all the studied composites were calculated based on Equation (8). The results are presented in Figure 4 and Table A2.

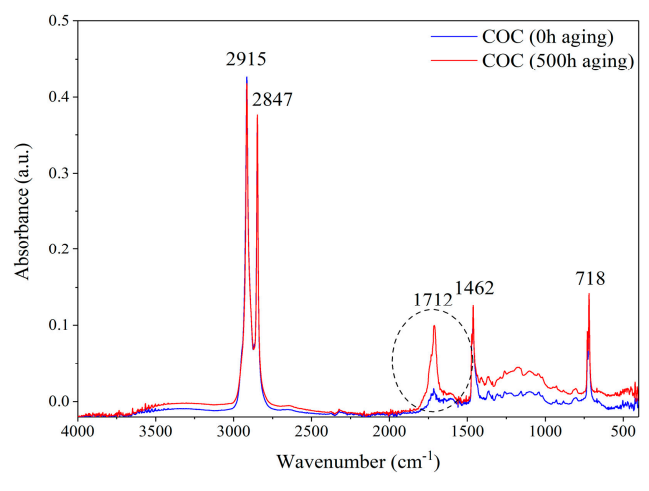

(a)

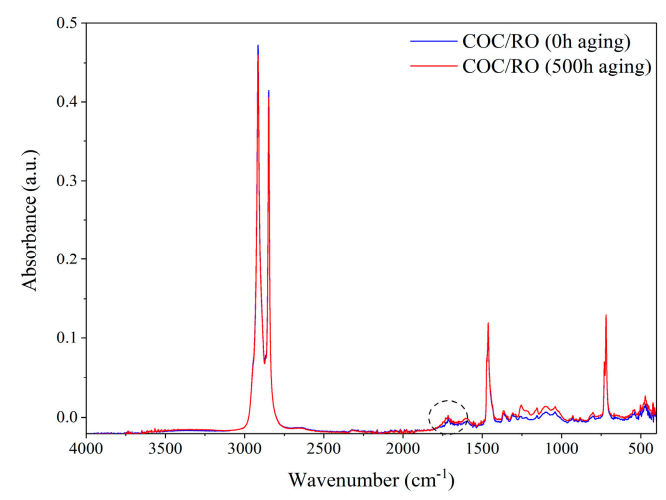

(b)

Figure 3. FTIR spectra of the COC copolymer composite (a) and COC/RO composite (b) before and after aging.

In the initial state of photodegradation (after $100 \mathrm{~h}$ ), the CI values were different from zero and similar for all the compounds. However, the CI values started to increase gradually with exposure to solar light, indicating progressive degradation of the macromolecules. As shown in Figure 4, the $\mathrm{CI}$ of the COC copolymer increased from $0.05(100 \mathrm{~h})$ to 0.4 after $500 \mathrm{~h}$ of irradiation, indicating that numerous carbonyl groups were generated on the surface of the unfilled COC. This can be explained by radical processes accelerated by UV light, and it was reflected by the low stability of the unprotected $\mathrm{COC}$. The most pronounced increase in the $\mathrm{CI}$ parameter was observed for neat $\mathrm{COC}$ and $\mathrm{COC} / \mathrm{BO}$, as their values after $500 \mathrm{~h}$ of aging were even double those of the other compounds. This means that neat $\mathrm{COC}$ is not resistant against prolonged exposure to solar light, whereas the brown ochre pigment may act as a pro-oxidant that accelerates the photodegradation of COC. In comparison, the other composites containing earth pigments were characterized by significantly slower and above all smaller increases in $\mathrm{CI}$, which proves that these pigments had a positive effect on the stability of COC exposed to solar light radiation. Most of the earth pigments protected the COC more effectively against solar irradiation than the lawson-based pigment studied in our previous work [27]. The aging coefficients of the COC/Golden Ochre pigment showed values of around 1 after $300 \mathrm{~h}$ of irradiation, whereas the COC copolymer containing organic-inorganic pigment was found to be around 0.8 after a similar duration of aging treatment. 
A homogenous distribution of pigment is important for ensuring uniform color and good mechanical properties. It is known that aggregates/agglomerates can act as stress concentrators in polymer materials, which may therefore be weaker than composites containing well-dispersed particles. Scanning electron microscopy (SEM) was used to determine the morphology of the applied earth pigments and their distribution in the COC matrix. Figure 5 shows digital photographs and SEM images of the earth pigment powders. Figure 6 shows SEM images and digital photographs of the COC copolymer with different earth pigments.

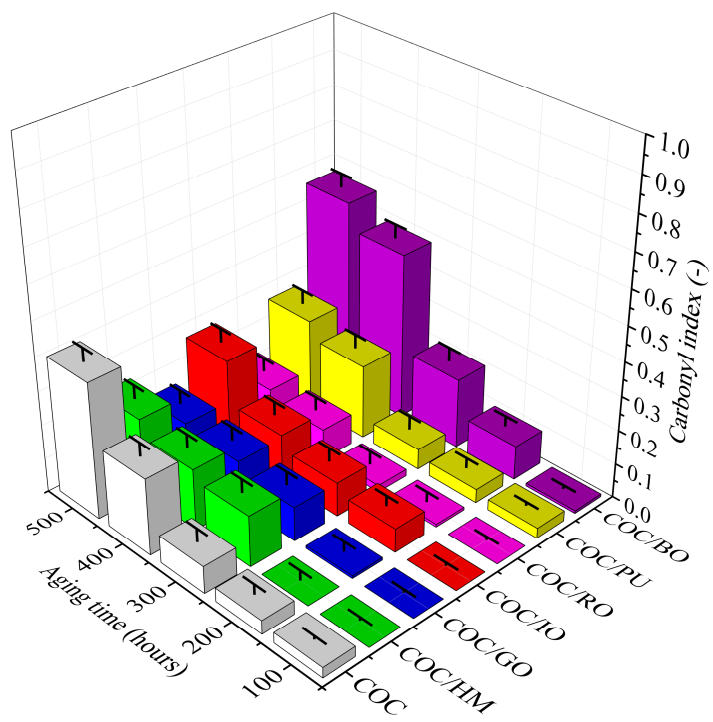

Figure 4. Carbonyl index (CI) parameters of the studied composites at different aging times.

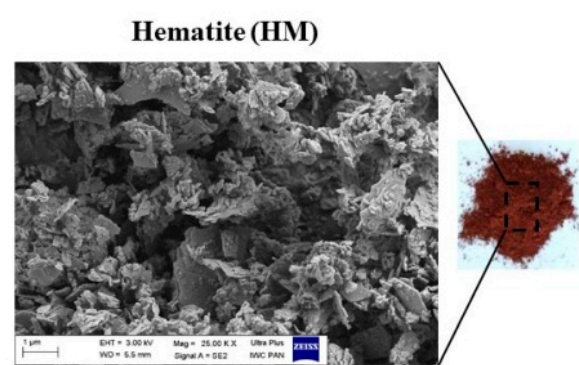

Golden ochre (GO)

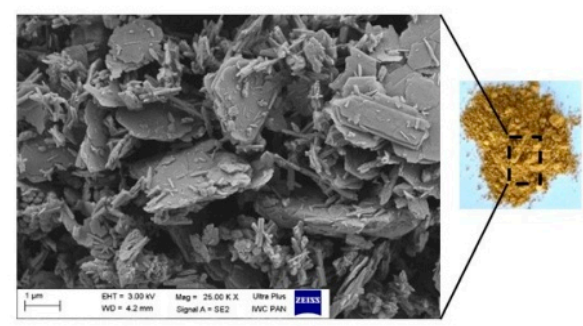

Iron ochre (IO)

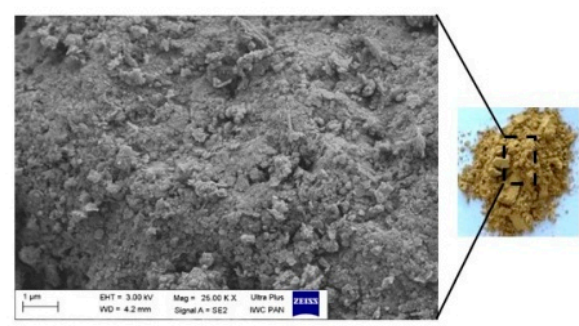

Red ochre (RO)

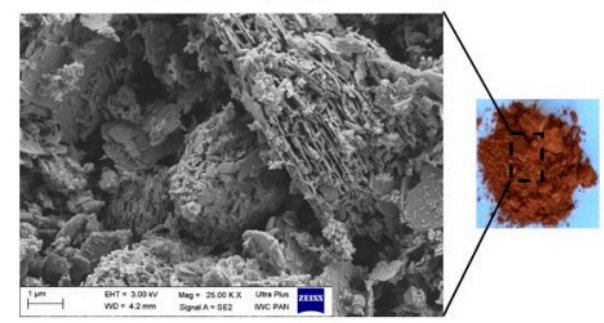

Brown ochre (BO)

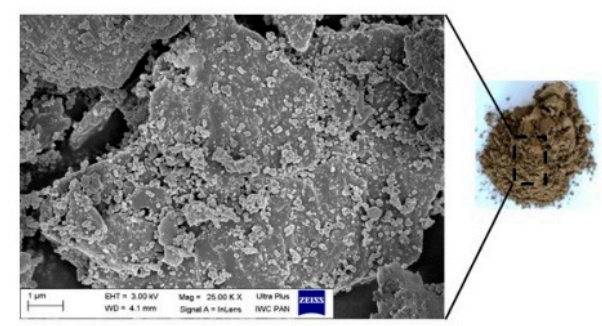

Puzzola(PU)

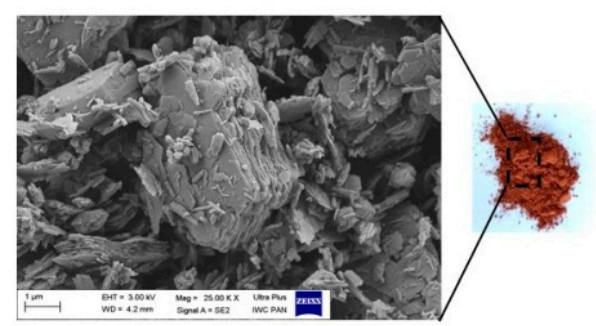

Figure 5. Scanning electron microscopy (SEM) images and digital photographs of the earth pigment powders. 


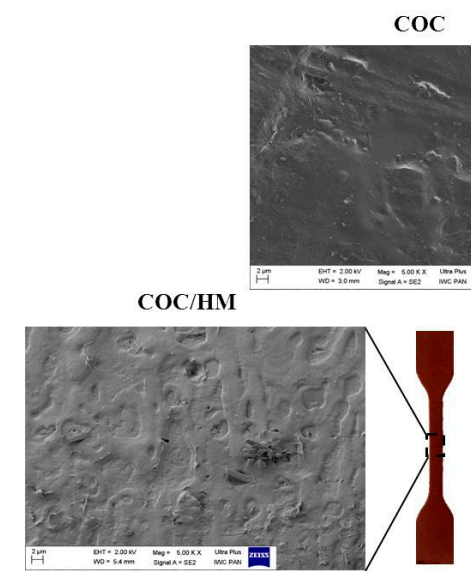

$\mathrm{COC} / \mathrm{GO}$

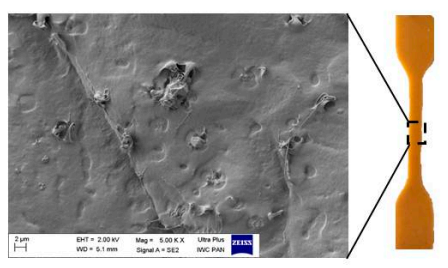

$\mathrm{COC} / \mathrm{IO}$

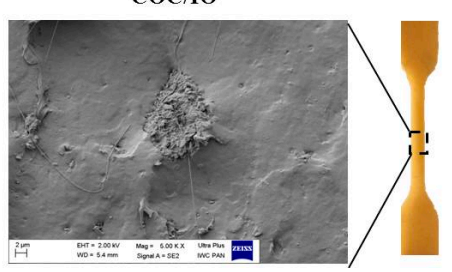

$\mathrm{COC} / \mathrm{RO}$

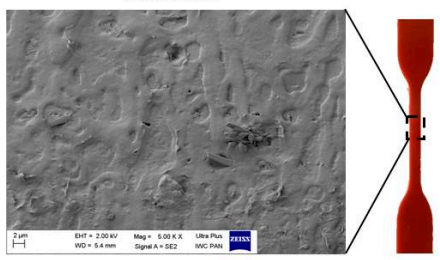

$\mathrm{COC} / \mathrm{BO}$

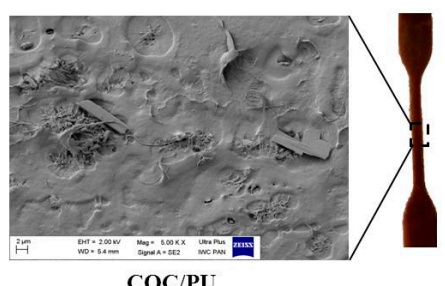

$\mathrm{COC} / \mathrm{PL}$

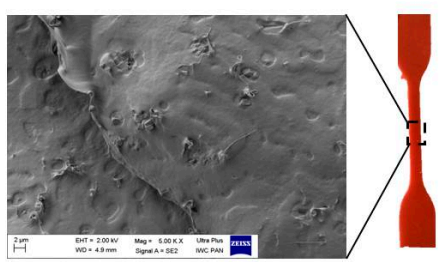

Figure 6. Scanning electron microscopy (SEM) images and digital photographs of the COC copolymer containing earth pigments.

Owing to the irregular nature of the fracture surface, it is difficult to describe the precise morphology of the pigments. However, the hematite (HM), gold ochre (GO), and brown ochre (BO) pigments clearly consisted of different types of particles (irregular plate-like and brick-like shapes), ranging from 0.5 up to a few $\mu \mathrm{m}$, which often formed aggregates. The iron ochre (IO) particles were shaped similarly to the gold and brown ochre particles. The SEM photographs show the IO powder to be composed of a mixture of individual platelets and some stacks of platelets, with a wide particle size distribution from 1 to $>5 \mu \mathrm{m}$. The iron ochre IO and puzzola (PU) pigments consisted of irregular, roughly shaped grains of varying dimensions, from 0.5 up to several microns.

The SEM images of cross-sections of the COC/pigment composites (Figure 6) show a homogenous distribution of colorant particles of rather uniform size. Morphology analysis revealed that some of the pigment particles were randomly dispersed in the COC copolymer, forming island-like agglomerates ranging in size from 2 to $\sim 5 \mu \mathrm{m}$. Despite the presence of some regions with higher concentrations of colorant, digital photographs of the polymer materials colored with $2 \mathrm{wt} \%$ of the selected pigments show uniform color. Moreover, the results of mechanical tests were similar for the COC/pigment composites and the reference sample (COC). These observations imply that the amount of colorant applied in this study is sufficient to achieve the desired color, while simultaneously preserving the initial strength of the polymer.

The progressive degradation of macromolecules under outdoor conditions is most visible in the sudden deterioration of the physical properties of composites. Therefore, the mechanical properties of the COC-filled compounds were evaluated before and after the aging process. The results are presented in Table 2. 
Table 2. Mechanical parameters of the studied composites in their initial state and after $500 \mathrm{~h}$ of aging (standard deviation of $\mathrm{Ts} \pm 0.7 \mathrm{MPa}, \mathrm{S}_{\mathrm{E} 100 \%} \pm 0.6 \mathrm{MPa}, \mathrm{E}_{\mathrm{B}} \pm 45 \%$ ).

\begin{tabular}{ccccc}
\hline \multicolumn{2}{c}{ Composite Name } & $\left.\mathbf{T}_{\mathbf{S}} \mathbf{( M P a}\right)$ & $\left.\mathbf{S}_{\mathbf{E 1 0 0} \%} \mathbf{( M P a}\right)$ & $\mathbf{E}_{\mathbf{B}} \mathbf{( \% )}$ \\
\hline \multirow{2}{*}{ COC } & Before aging & 40.5 & 9.5 & 802 \\
& After aging & 12.7 & 10.3 & 415 \\
COC/HM & Before aging & 41.5 & 9.4 & 819 \\
& After aging & 40.2 & 8.7 & 801 \\
COC/GO & Before aging & 40.4 & 9.8 & 809 \\
& After aging & 39.9 & 8.5 & 771 \\
COC/IO & Before aging & 41.4 & 9.3 & 831 \\
& After aging & 21.3 & 8.8 & 556 \\
COC/RO & Before aging & 42.4 & 9.7 & 859 \\
& After aging & 34.4 & 8.6 & 717 \\
COC/BO & Before aging & 41.7 & 9.4 & 807 \\
& After aging & 15.2 & 10.2 & 410 \\
COC/PU & Before aging & 41.7 & 9.7 & 826 \\
& After aging & 39.0 & 8.6 & 822 \\
\hline
\end{tabular}

$\mathrm{T}_{\mathrm{S}}$, tensile strength; $\mathrm{S}_{\mathrm{E} 100 \%}$, stress at $100 \%$ elongation; $\mathrm{E}_{\mathrm{B}}$, elongation at break.

The pure COC composites reached tensile strength values of about $40 \mathrm{MPa}$. Similar results have been obtained previously by other authors for the same COC copolymer $[30,37,38]$. Exposure to solar irradiation was found reduce the tensile strength and elongation at break of the composites. In the cases of unprotected $\mathrm{COC}$ and $\mathrm{COC} / \mathrm{BO}$ composites, these reductions were significant. This confirmed our previous observations. Along with the reduction of elongation at break, the increase in the modulus also testified to their advanced degradation. Previous reports in the literature have similarly noted a worsening of the mechanical properties of ethylene-norbornene copolymer after exposure to UV radiation $[39,40]$, suggesting that COC may also not be resistant to prolonged exposure to UV radiation. However, our results indicate that the application of earth pigments may protect COC against the negative effects of solar irradiation, since the tensile strength and elongation at break parameters of the other COC-filled compounds remained almost unchanged. As an indication of the effect of the earth pigments the on the mechanical properties of the aged COC composites, the aging coefficient $(\mathrm{K})$ determined for each sample is presented in Figure 7.

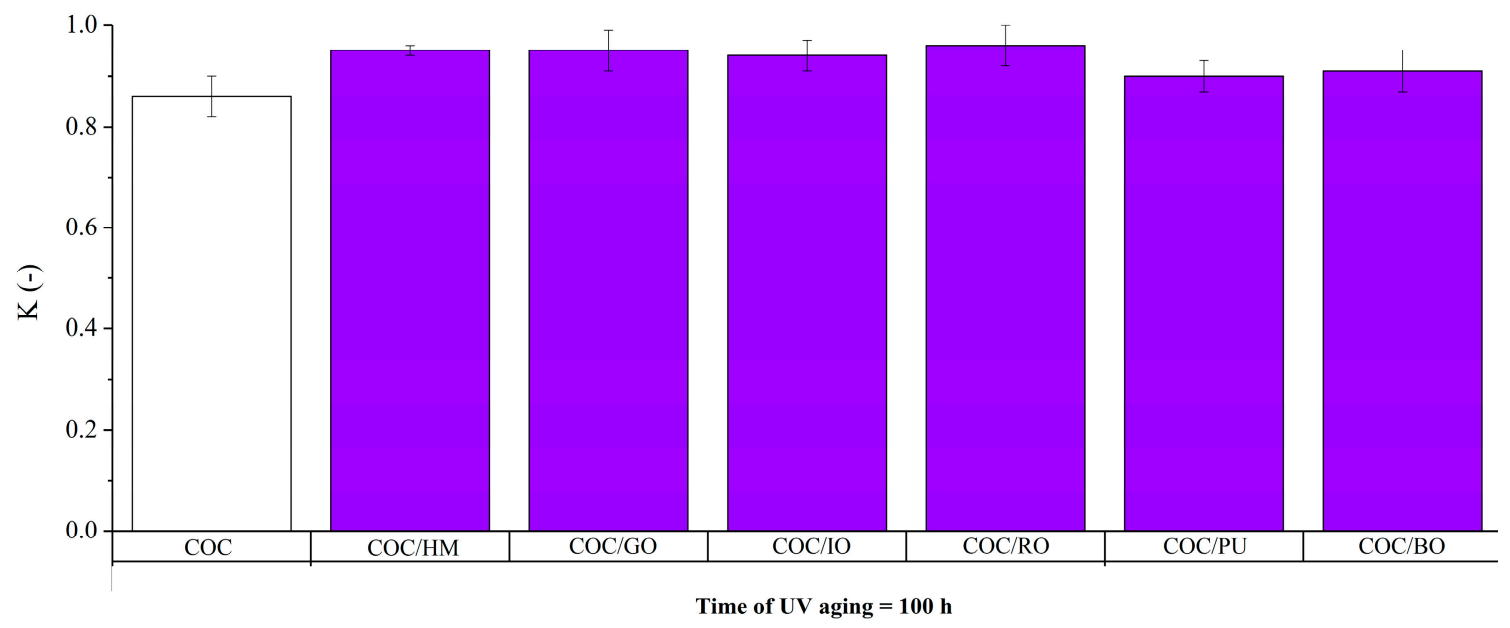

(a)

Figure 7. Cont. 


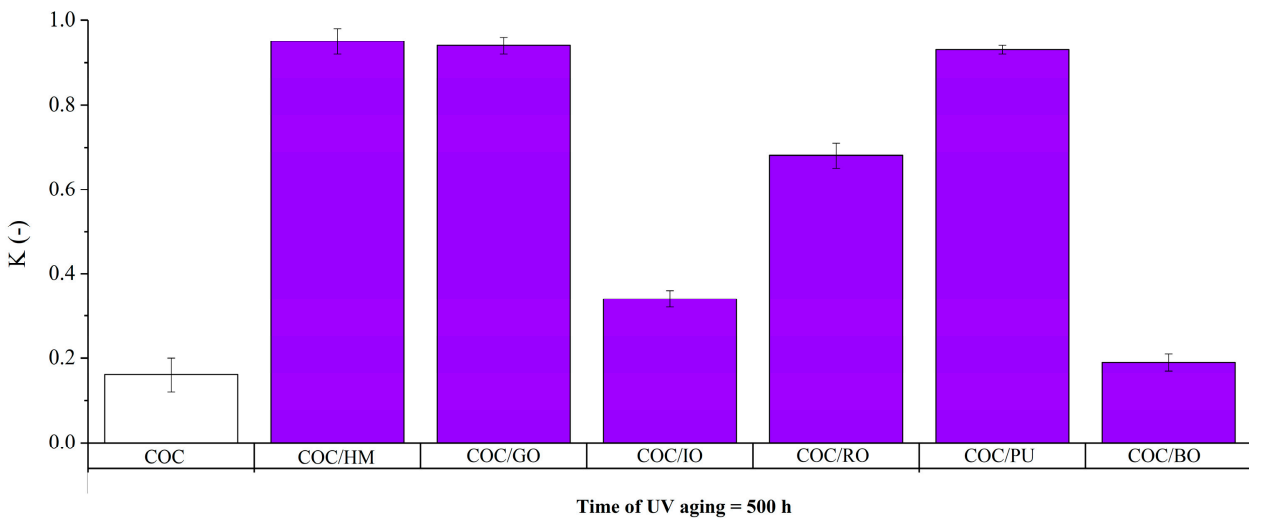

(b)

Figure 7. Aging factor (K) of the studied composites at different aging times: (a) $100 \mathrm{~h}$; and (b) $500 \mathrm{~h}$.

When the $\mathrm{K}$ value was close to 1 , the composite was resistant to unfavorable conditions and its mechanical properties remained stable. However, when the $\mathrm{K}$ value was closer to 0 , the composites underwent significant degradation. Based on our results, it can be concluded that after $100 \mathrm{~h}$ of aging the mechanical properties of all the composites were unchanged, but after $500 \mathrm{~h}$ the $\mathrm{K}$ values for COC, $\mathrm{COC} / \mathrm{IO}$, and $\mathrm{COC} / \mathrm{BO}$ reduced significantly. Nonetheless, the K parameters for most of the composites with different pigments remained almost unchanged after $500 \mathrm{~h}$ of aging. Based on the mechanical changes following exposure to solar light, the protection efficiencies of the individual earth pigments can be summarized as follows: $\mathrm{HM}>\mathrm{GO}>\mathrm{PU}>\mathrm{RO}>\mathrm{IO}>\mathrm{BO}$. These results are in good agreement with those obtained for surface discoloration and the CI.

In the next part of study, the total surface energy and its polar and dispersive components were calculated from the contact angles (Figure 8).

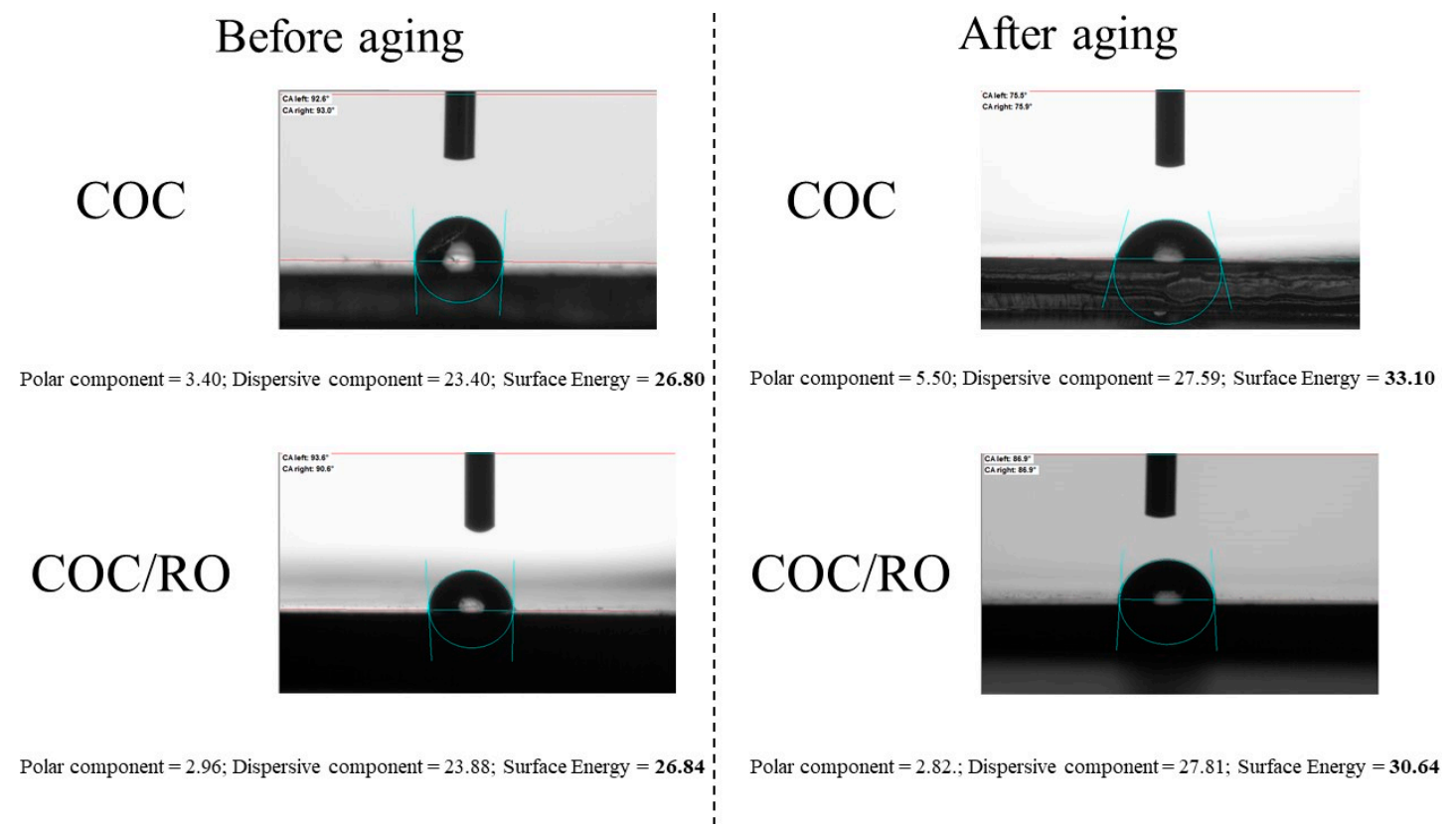

Figure 8. Surface energy of neat COC composite and COC filled with red ochre before and after $500 \mathrm{~h}$ of irradiation (images show the contact angle for water).

In the case of pure COC, the dispersive $\left(23.40 \mathrm{~mJ} / \mathrm{m}^{2}\right)$ and polar $\left(3.40 \mathrm{~mJ} / \mathrm{m}^{2}\right)$ components of surface energy after $500 \mathrm{~h}$ of aging increased rapidly, up to 27.59 and $5.50 \mathrm{~mJ} / \mathrm{m}^{2}$, respectively. The total surface energy of the COC sample changed in a similar way, increasing from 26.80 to $33.10 \mathrm{~mJ} / \mathrm{m}^{2}$ as result 
of irradiation. After the addition of red ochre pigment, the polar and dispersive components of the $\mathrm{COC} / \mathrm{RO}$ surface energy changed slightly in comparison to the reference sample. After $500 \mathrm{~h}$ of aging, the polar component remained almost unchanged, whereas the dispersive components rose from 23.88 to $27.81 \mathrm{~mJ} / \mathrm{m}^{2}$. From these results, it can be concluded that during aging more polar groups were generated on the surface of the reference sample, resulting in a larger increase in surface energy compared to the sample with red ochre pigment.

\subsection{Thermal Stability and Flammability}

Figures 9, 10, A1 and A2 show thermogravimetric (TGA) and derivate thermogravimetric (DTG) curves for pure COC and COC loaded with 2 phr of different earth pigments, measured in different atmospheres. Table 3 summarizes thermal degradation temperatures corresponding to $5 \%\left(\mathrm{~T}_{05 \%}\right)$, $20 \%\left(\mathrm{~T}_{20} \%\right)$, and $50 \%$ weight loss $\left(\mathrm{T}_{50 \%}\right)$. From the TGA data in Figure 9, it can be observed that there was hardly any difference between the considered composites in terms of thermal stability measured in an inert atmosphere. However, the $\mathrm{T}_{20 \%}$ and $\mathrm{T}_{50 \%}$ of pure COC were slightly lower than those for COC containing puzzola pigment. This was most likely due to the presence of different metals and salts in the chemical composition of this pigment, which may enhance the resistance of COC composites to thermal decomposition. The TGA measurements presented in Figure 10 show that incorporation of earth pigments enhanced the stability of the COC composites at elevated temperatures in the presence of air. The $\mathrm{T}_{50 \%}$ parameter of the COC-filled composites in an air atmosphere was up to $30^{\circ} \mathrm{C}$ higher than that for pure COC.

The effect of the different earth pigments on the combustion of the COC copolymer was investigated by microscale combustion calorimetry (MCC). This test is now commonly used as a bench-scale method for investigating the combustion behavior of different polymeric materials [41,42]. The MCC test provides important parameters for determining the flame-retardant properties of the materials, such as the heat release rate (HRR), total heat release (THR), and heat release capacity (HRC). The heat release rate (HRR) curves of the COC composites obtained from MCC tests are presented in Figure 11. The corresponding data are listed in Table 4.

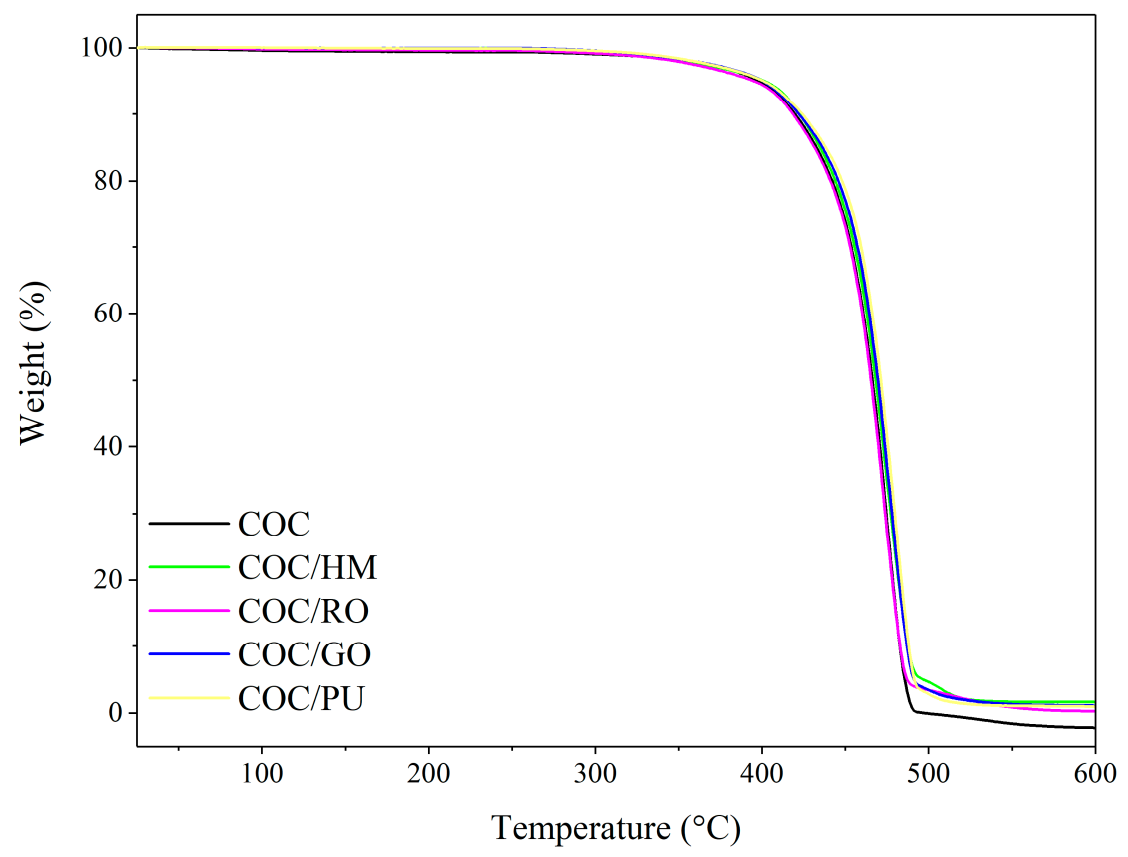

Figure 9. Thermogravimetric (TGA) curves obtained for COC composites filled with different earth pigments measured in an inert atmosphere. 


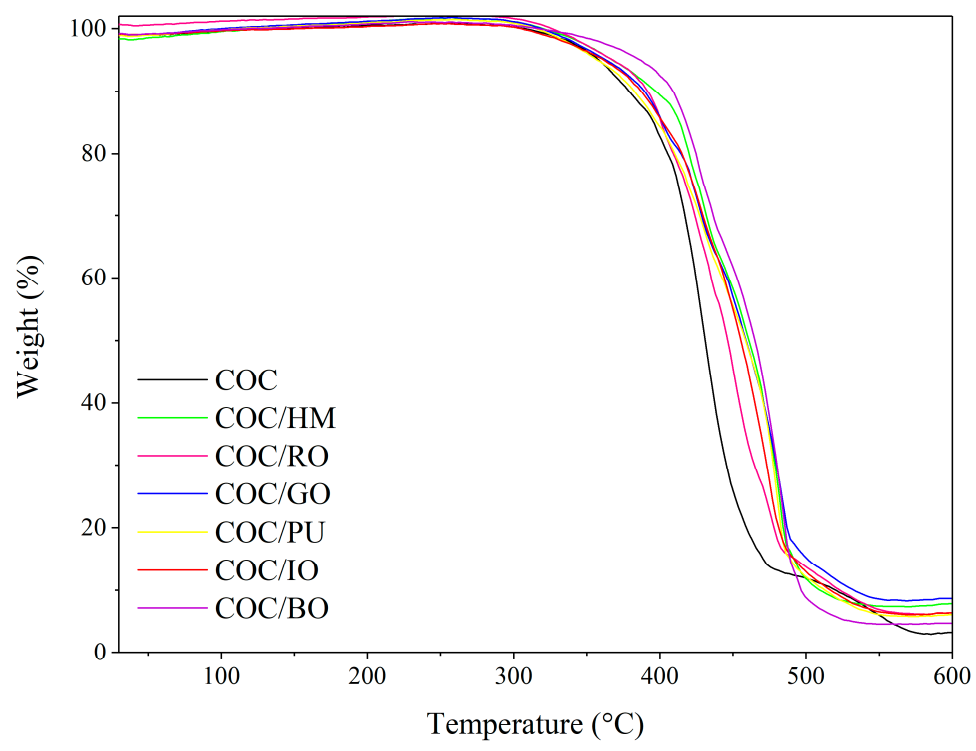

Figure 10. TGA curves obtained for COC composites filled with different earth pigments measured in air atmosphere.

Table 3. Thermal decomposition temperatures for COC composites filled with different earth pigments (standard deviation of $\mathrm{T}_{05,20,50 \%}= \pm 3{ }^{\circ} \mathrm{C}$ ).

\begin{tabular}{cccc}
\hline Composite Name & $\mathbf{T}_{\mathbf{0 5} \%}\left({ }^{\circ} \mathbf{C}\right)$ & $\mathbf{T}_{\mathbf{2 0} \%}\left({ }^{\circ} \mathbf{C}\right)$ & $\mathbf{T}_{\mathbf{5 0} \%}\left({ }^{\circ} \mathbf{C}\right)$ \\
\hline \multicolumn{4}{c}{ Argon atmosphere } \\
COC & 398 & 442 & 466 \\
COC/HM & 401 & 444 & 468 \\
COC/GO & 400 & 446 & 470 \\
COC/RO & 398 & 442 & 465 \\
COC/PU & 400 & 449 & 471 \\
\multicolumn{5}{c}{ Air atmosphere } \\
COC/HM & 359 & 406 & \\
COC/GO & 370 & 422 & 431 \\
COC/RO & 365 & 415 & 462 \\
COC/PU & 368 & 411 & 448 \\
& 359 & 412 & 459
\end{tabular}

$\mathrm{T}_{05 \%}, \mathrm{~T}_{20 \%}, \mathrm{~T}_{50 \%}$, thermal decomposition temperatures degrading $5 \%, 20 \%$, and $50 \%$ of sample, respectively.

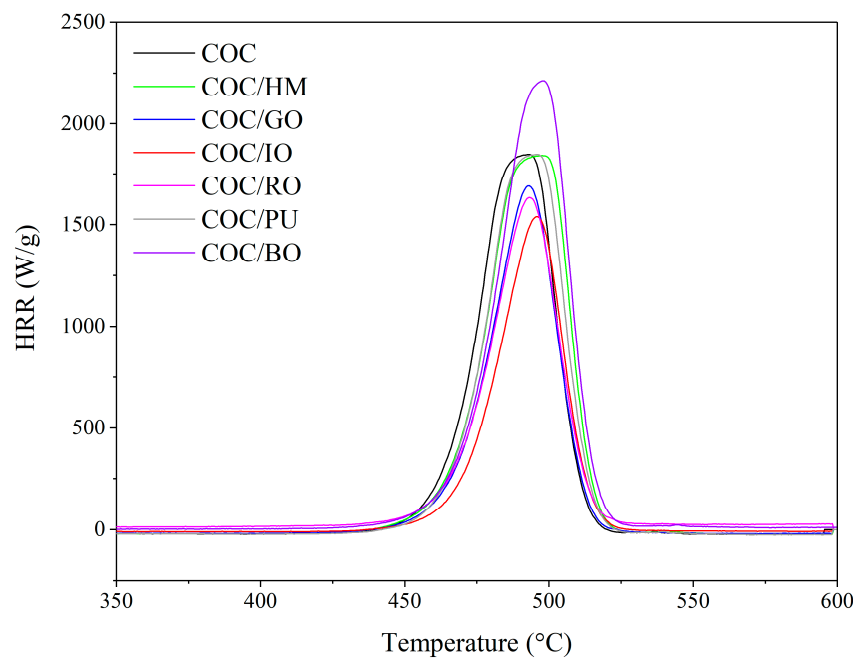

Figure 11. Heat release rate versus temperature obtained for COC composites with different earth pigments. 
Table 4. Microscale combustion calorimetry analysis data.

\begin{tabular}{cccc}
\hline Compound & HRR $(\mathbf{W} / \mathbf{g})$ & THR $(\mathbf{k J} / \mathbf{g})$ & HRC $(\mathbf{J} / \mathbf{g K})$ \\
\hline COC & $1857 \pm 93$ & $79 \pm 4$ & $1851 \pm 93$ \\
COC/HM & $1839 \pm 93$ & $64 \pm 3$ & $1845 \pm 92$ \\
COC/GO & $1685 \pm 84$ & $49 \pm 3$ & $1620 \pm 81$ \\
COC/IO & $1526 \pm 76$ & $43 \pm 2$ & $1530 \pm 77$ \\
COC/RO & $1633 \pm 82$ & $47 \pm 2$ & $1599 \pm 80$ \\
COC/BO & $2210 \pm 111$ & $67 \pm 3$ & $2188 \pm 109$ \\
COC/PU & $1843 \pm 92$ & $61 \pm 3$ & $1853 \pm 93$ \\
\hline
\end{tabular}

HRR, heat release rate; THR, total heat release; HRC, heat release capacity.

It is important to note that the earth pigments reduced the fire hazard of the $\mathrm{COC}$, in terms of the HRR, which is a propelling force of fire [43]. As can be seen in Figure 11, the HRR peak for the neat copolymer was higher than most of the COC composites filled with earth pigments. This means that the application of earth pigments may reduce the flammability of $\mathrm{COC}$ composite materials. On the other hand, the use of $\mathrm{BO}$ had the opposite effect, indicating that brown ochre may support combustion of COC to some extent. Regardless of the chemical structure of the earth pigments, in most cases, the application of pigments as colorants for COC clearly reduced both the total heat release and the heat release capacity of the composites. It should be emphasized that the amount of the pigments used was only $2 \mathrm{phr}$. The most pronounced reduction in the flammability parameters was observed for COC composite filled with iron ochre. In this case, the THR and HRC parameters of the COC compound were reduced after the application of IO from 79 and 1851 (neat COC) to 43 and $1530 \mathrm{~J} / \mathrm{gK}$ $(\mathrm{COC} / \mathrm{IO})$, respectively. In general, the flammability of the COC composites filled with various earth pigments can be ordered as follows, starting from the least flammable: $\mathrm{COC} / \mathrm{IO}<\mathrm{COC} / \mathrm{RO}<\mathrm{COC} / \mathrm{GO}$ $<\mathrm{COC} / \mathrm{HM}<\mathrm{COC} / \mathrm{PU}<\mathrm{COC}<\mathrm{COC} / \mathrm{BO}$. The improved flame safety of the COC composites upon the incorporation of earth pigments may result from the presence in their structure of metal oxides, including transition metals. Generally, most transition-group metals possess catalytic activity and can alter the rates of processes including thermal degradation noticeably. Iron oxides that enter the gas zone are treated as free radical scavengers, interrupting the high-energy reactions that occur in this zone. Previous studies [44-46] have shown that the incorporation of fillers containing metal ions, including mineral pigments, may have a considerable influence on the fire hazard characteristics of polymer composites. In the present work, we also observed that earth pigments containing transition metal oxides can reduce COC flammability.

\section{Conclusions}

In this study, we produced a series of new multicolor ethylene-norbornene composites by introducing various natural earth pigments into COC copolymer via melt mixing. The composites were subjected to artificial solar ageing. The characteristics of the composites after exposure to sunlight were examined by Fourier transform-infrared spectroscopy, surface energy measurement, mechanical tests, and scanning electron microscopy. The earth pigments were found to have a protective effect on the polymer matrix, by comparison to the pure copolymer. The COC-filled composites were less susceptible to degradation compared to the uncolored copolymer, as evidenced by negligible changes in their color characteristics and surface energy, as well as by their very high ageing factors after 100, 200, 300, 400, and $500 \mathrm{~h}$ of aging in the full sunlight spectrum. It can be concluded that the earth pigments effectively absorbed part of the radiation, stabilizing the whole composite. Moreover, thermogravimetric and microcombustion calorimetry analyses revealed that the COC composites colored with earth pigments remained stable when subjected to elevated temperatures and their resistant to flame was improved. These comprehensive studies suggest that the application of multicolor earth pigments such as hematite, gold ochre, and red ochre may be an effective way to protect cycloolefin copolymer against the negative effects of solar irradiation, while iron and red ochres may also strongly enhance the flame retardancy 
of colored COC. These results open the way for the preparation of multicolor cycloolefin composites with improved light stability and flame retardancy, which could be used in packaging materials.

Author Contributions: Conceptualization, Methodology, Investigation, Data curation, Visualization, and Writing - original draft preparation, B.S.; Investigation and Data curation, M.K.; Investigation and Data curation, P.R.; Investigation and Data curation, W.Ż.; and Conceptualization, Methodology, Investigation, Data curation, Visualization, Writing - original draft preparation, and Supervision, A.M. All authors have read and agreed to the published version of the manuscript.

Funding: This research received no external funding.

Conflicts of Interest: The authors declare no conflict of interest.

\section{Appendix A}

Table A1. Total color change $(\Delta \mathrm{E})$ parameter of samples exposed to different aging times.

\begin{tabular}{cccccc}
\hline \multirow{2}{*}{ Compound } & \multicolumn{5}{c}{$\boldsymbol{\Delta E}$} \\
\cline { 2 - 6 } & $\mathbf{1 0 0} \mathbf{h}$ & $\mathbf{2 0 0} \mathbf{h}$ & $\mathbf{3 0 0} \mathbf{h}$ & $\mathbf{4 0 0} \mathbf{h}$ & $\mathbf{5 0 0} \mathbf{h}$ \\
\hline $\mathrm{COC}$ & 0.50 & 0.56 & 0.60 & 0.64 & 0.70 \\
$\mathrm{COC} / \mathrm{HM}$ & 0.20 & 0.23 & 1.00 & 1.30 & 1.50 \\
$\mathrm{COC} / \mathrm{GO}$ & 0.30 & 0.55 & 0.56 & 0.60 & 0.66 \\
$\mathrm{COC} / \mathrm{IO}$ & 0.60 & 1.00 & 1.10 & 1.20 & 1.30 \\
$\mathrm{COC} / \mathrm{RO}$ & 0.20 & 0.50 & 0.60 & 0.65 & 0.70 \\
$\mathrm{COC} / \mathrm{BO}$ & 0.40 & 0.80 & 2.50 & 3.59 & 5.32 \\
$\mathrm{COC} / \mathrm{PU}$ & 0.50 & 1.20 & 1.67 & 1.86 & 1.92 \\
\hline
\end{tabular}

Table A2. Carbonyl index (CI) parameter of samples exposed to different aging times.

\begin{tabular}{cccccc}
\hline \multirow{2}{*}{ Compound } & \multicolumn{5}{c}{ CI } \\
\cline { 2 - 6 } & $\mathbf{1 0 0} \mathbf{h}$ & $\mathbf{2 0 0} \mathbf{h}$ & $\mathbf{3 0 0} \mathbf{h}$ & $\mathbf{4 0 0} \mathbf{h}$ & $\mathbf{5 0 0} \mathbf{h}$ \\
\hline $\mathrm{COC}$ & 0.03 & 0.04 & 0.08 & 0.23 & 0.40 \\
$\mathrm{COC} / \mathrm{HM}$ & 0.00 & 0.00 & 0.15 & 0.18 & 0.23 \\
$\mathrm{COC} / \mathrm{GO}$ & 0.00 & 0.01 & 0.10 & 0.13 & 0.15 \\
$\mathrm{COC} / \mathrm{IO}$ & 0.00 & 0.07 & 0.10 & 0.14 & 0.27 \\
$\mathrm{COC} / \mathrm{RO}$ & 0.00 & 0.01 & 0.02 & 0.09 & 0.11 \\
$\mathrm{COC} / \mathrm{BO}$ & 0.01 & 0.10 & 0.21 & 0.49 & 0.56 \\
$\mathrm{COC} / \mathrm{PU}$ & 0.03 & 0.04 & 0.06 & 0.22 & 0.27 \\
\hline
\end{tabular}

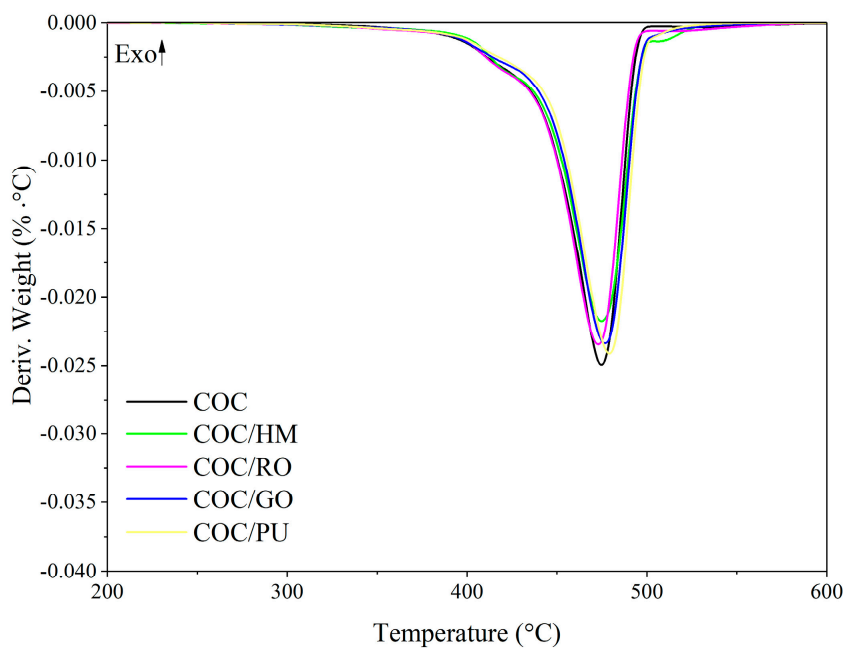

Figure A1. Derivate thermogravimetric (DTG) curves obtained for COC composites filled with different earth pigments measured in an inert atmosphere. 


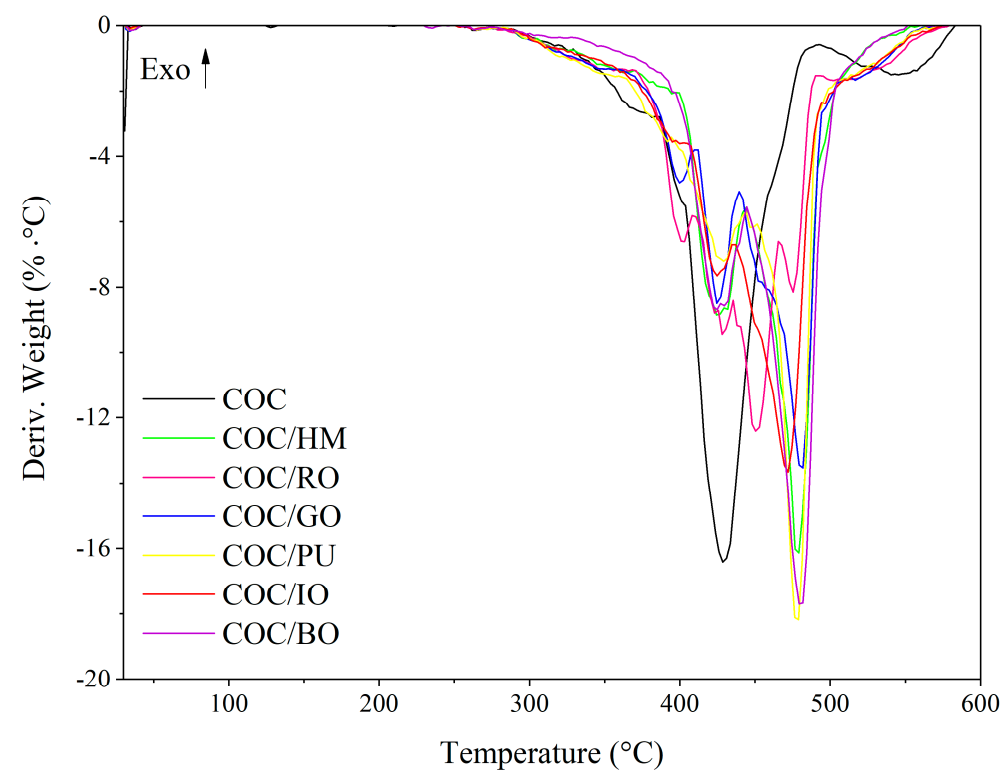

Figure A2. Derivate thermogravimetric (DTG) curves obtained for COC composites filled with different earth pigments measured in an air atmosphere.

\section{References}

1. Garcia, A.; Losar, M.; Calbo, J.; Tena, M.A.; Monros, G. Low-toxicity red ceramic pigments for porcelainised stoneware from lanthanide-cerianite solid solutions. Green Chem. 2001, 3, 238-242. [CrossRef]

2. Tesitelova, K.; Sulcova, P. Synthesis and study of $\mathrm{Bi}_{2} \mathrm{Ce}_{2} \mathrm{O}_{7}$ as inorganic pigment. J. Therm Anal Calorim. 2016, 125, 1047-1052. [CrossRef]

3. Furukawa, S.; Masui, T.; Imanaka, N. Synthesis of new environment-friendly yellow pigments. J. Alloys Compd. 2006, 418, 255-258. [CrossRef]

4. Marzec, A.; Szadkowski, B.; Rogowski, J.; Maniukiewicz, W.; Szynkowska, M.I.; Zaborski, M. Characteristics of hybrid pigments made from alizarin dye on mixed oxide host. Materials 2019, 12, 360. [CrossRef]

5. Kohno, Y.; Totsuka, K.; Ikoma, S.; Yoda, K.; Shibata, M.; Matsushima, R.; Tomita, Y.; Maeda, Y.; Kobayashi, K. Photostability enhancement of anionic natural dye by intercalation into hydrotalcite. J. Colloid Interface Sci. 2009, 337, 117-121. [CrossRef]

6. Girdthep, S.; Sirirak, J.; Daranarong, D.; Daengngern, R.; Chayabutra, S. Physico-chemical characterization of natural lake pigments obtained from Caesalpinia Sappan Linn. and their composite films for poly(lactic acid)-based packaging material. Dyes Pigments 2018, 157, 27-39. [CrossRef]

7. Marzec, A.; Szadkowski, B.; Rogowski, J.; Maniukiewicz, W.; Zaborski, M. Characterization and structure-property relationships of organic-inorganic hybrid composites based on aluminum-magnesium hydroxycarbonate and azo chromophore. Molecules 2019, 24, 880. [CrossRef]

8. Seentrakoon, B.; Junhasavasdikul, B.; Chavasiri, W. Enhanced UV-protection andantibacterial properties of natural rubber/rutileeTiO2 nanocomposites. Polym. Degrad. Stab. 2013, 98, 566-578. [CrossRef]

9. Konta, J. Clay and man: Clay raw materials in the service of man. Appl. Clay Sci. 1995, 10, 275-335. [CrossRef]

10. Sreeram, K.J.; Kumeresan, S.; Radhika, S.; Sundar, V.J.; Muralidharana, C.; Nari, B.U.; Ramasami, T. Use of mixed rare earth oxides as environmentally benign pigments. Dyes Pigments 2008, 76, 243-248. [CrossRef]

11. Abbasi, A.; Ghanbari, D.; Salavati-Niasari, M.; Hamadanian, M. Photo-degradation of methylene blue: Photocatalyst and magnetic investigation of $\mathrm{Fe}_{2} \mathrm{O}_{3}-\mathrm{TiO}_{2}$ nanoparticles and nanocomposites. J. Mater. Sci. Mater. Electron. 2016, 27, 4800-4809. [CrossRef]

12. Raj, A.K.; Rao, P.P.; Sreena, T.S.; Thara, T.A. Pigmentary colors from yellow to red in $\mathrm{Bi}_{2} \mathrm{Ce}_{2} \mathrm{O}_{7}$ by rare earth ion substitutions as possible high NIR reflecting pigments. Dyes Pigments 2019, 160, 177-187. [CrossRef]

13. Laskowska, A.; Marzec, A.; Boiteux, G.; Zaborski, M.; Gain, O.; Serghei, A. Investigations of Nitrile Rubber Composites Containing Imidazolium Ionic Liquids. Macromol. Symp. 2014, 341, 18-25. [CrossRef] 
14. Camlibel, N.O.; Arik, B.; Avinc, O.; Yavas, A. Antibacterial, UV protection, flame retardancy and coloration properties of cotton fabrics coated with polyacrylate polymer containing various iron ores. J. Text. Inst. 2018, 109, 1424-1433. [CrossRef]

15. Yousif, E.; Haddad, R. Photodegradation and photostabilization of polymers, especially polystyrene. SpringerPlus 2013, 2, 398. [CrossRef]

16. Herzig, E.; Johlitz, M.; Lion, A. Ageing Phenomena in Polymers: A Short Survey. In Adhesive Joints: Ageing and Durability of Epoxies and Polyurethanes; Possart, W., Brede, M., Eds.; Wiley-VCH Verlag GmbH: Weinheim, Germany, 2018; pp. 167-204.

17. Turton, T.J.; White, J.R. Effect of stabilizer and pigment on photo-degradation depth profiles in polypropylene. Polym. Degrad. Stab. 2001, 74, 559-568. [CrossRef]

18. Saron, C.; Falisberti, M.I.; Zulli, F.; Giordano, M. Influence of diazo pigment on polycarbonate photodegradation. J. Appl. Polym. Sci. 2008, 107, 1071-1079. [CrossRef]

19. Anna, P.; Bertalan, G.; Marosi, G.; Ravadits, I.; Maatoug, M.A. Effect of interface modification on the photo-stability of pigmented polyethylene films. Polym. Degrad. Stab. 2011, 73, 463-466. [CrossRef]

20. Haug, S.P.; Andres, C.J.; Moore, B.K. Color stability and colorant effect on maxillofacial elastomers. Part III: Weathering effect on color. J. Prosthet. Dent. 1999, 81, 431-438. [CrossRef]

21. Kiat-amnuay, S.; Lemon, J.C.; Powers, J.M. Effect of opacifiers on color stability of pigmented maxillofacial silicone A-2186 subjected to artificial aging. J. Prosthet. Dent. 2002, 11, 109-116. [CrossRef]

22. Camargo, P.H.C.; Satyanarayana, K.G.; Wypych, F. Nanocomposites: Synthesis, structure, properties and new application opportunities. Mater Res. 2009, 12, 1-39. [CrossRef]

23. Rajadurai, A. Thermo-mechanical characterization of siliconized E-glass fiber/hematite particles reinforced epoxy resin hybrid composite. Appl. Surf. Sci. 2016, 384, 99-106.

24. Brocca, D.; Arvin, E.; Mosbaek, H. Identification of organic compounds migrating from polyethylene pipelines into drinking water. Water Res. 2002, 36, 3675-3680. [CrossRef]

25. Masek, A.; Latos, M.; Piotrowska, M.; Zaborski, M. The potential of quercetin as an effective natural antioxidant and indicator for packaging materials. Food Packag. Shelf Life 2018, 16, 51-58. [CrossRef]

26. Marzec, A.; Szadkowski, B.; Rogowski, J.; Maniukiewicz, W.; Zaborski, M. New organic-inorganic hybrids as multifunctional additives to improve ethylene-norbornene (EN) composite stability. Polym. Degrad. Stab. 2019, 160, 110-119. [CrossRef]

27. Marzec, A.; Szadkowski, B. Improved aging stability of ethylene-norbornene composites filled with lawsone-based hybrid pigment. Polymers 2019, 11, 723. [CrossRef] [PubMed]

28. Masłowski, M.; Miedzianowska, J.; Strzelec, K. Natural rubber biocomposites containing corn, barley and wheat straw. Polym. Test. 2017, 63, 84-91. [CrossRef]

29. Kaelble, D.H. Dispersion-polar surface tension properties of organic solids. J. Adhes. 1970, 2, 66-81. [CrossRef]

30. Marzec, A.; Szadkowski, B.; Kuśmierek, M.; Rogowski, J.; Maniukiewicz, W.; Rybiński, P.; Zaborski, M. Impact of organic-inorganic color additive on the properties of ethylene-norbornene copolymer. Polym. Test. 2020, 82, 106290. [CrossRef]

31. Schmidt, H.; Twarowska-Schmidt, K. Effect of pigments on the photooxidative degradation of polypropylene fibers. Fibres Text. East. Eur. 1997, 5, 51-52.

32. Klemchuk, P.P. Influence of pigments on the light stability of polymers: A critical review. Polym. Photochem. 1982, 3, 1-27. [CrossRef]

33. Allen, N.S. Photofading and light stability of dyed and pigmented polymers. Polym. Degrad. Stab. 1994, 44, 357-374. [CrossRef]

34. Stark, N.M.; Matuana, L.M. Influence of photostabilizers on wood flour-HDPE composites exposed to xenon-arc radiation with and without water spray. Polym. Degrad. Stab. 2006, 91, 3048-3056. [CrossRef]

35. Du, H.; Wang, W.; Wang, Q.; Zhang, Z.; Sui, S.; Zhang, Y. Effect of pigments on the UV degradation of wood-flour/HDPE composites. J. Appl. Polym. Sci. 2010, 118, 1068-1076. [CrossRef]

36. Du, W.; Xu, Y.; Wang, Y. Photoinduced degradation of orange-II on different iron (hydro) oxides in aqueous suspension: Rate enhancement on addition of hydrogen peroxide, silver nitrate, and sodium fluoride. Langmuir 2008, 24, 175-181. [CrossRef]

37. Cichosz, S.; Masek, A.; Wolski, K. Innovative cellulose fibres reinforced ethylene-norbornene copolymer composites of an increased degradation potential. Polym. Degrad. Stab. 2019, 159, 174-183. [CrossRef] 
38. Masek, A.; Chrzescijanska, E.; Diakowska, K.; Zaborski, M. Application of $\beta$-carotene, a natural flavonoid dye, to polymeric materials as a natural antioxidant and determination of its characteristics using cyclic voltammetry and FTIR spectroscopy. Int. J. Electrochem. Sci. 2015, 10, 3372-3386.

39. Marzec, A.; Laskowska, A.; Boiteux, G.; Zaborski, M.; Gain, O.; Serghei, A. Study on weather aging of nitrile rubber composites containing imidazolium ionic liquids. Macromol. Symp. 2014, 342, 25-34. [CrossRef]

40. Marzec, A.; Chrześcijańska, E.; Boruszczak, Z.; Zaborski, M.; Laskowska, A.; Boiteux, G.; Gain, O. Novel dyed ethylene-norbornene composites with enhanced aging resistance. Polym. Degrad. Stab. 2016, 123, 137-145. [CrossRef]

41. Lyon, R.E.; Walters, R.N.; Stoliarov, S.I. Screening flame retardants for plastics using microscale combustion calorimetry. Polym. Eng. Sci. 2007, 41, 1501-1510. [CrossRef]

42. Lu, H.; Wilkie, C.A. Fire performance of flame retardant polypropylene and polystyrene composites screened with microscale combustion calorimetry. Polym. Advan. Technol. 2011, 22, 14-21. [CrossRef]

43. Pająk, A.; Rybiński, P.; Janowska, G.; Kucharska-Jastrząbek, A. The thermal properties and the flammability of pigmented elastomeric materials. J. Thermal. Anal. Calorim. 2014, 117, 789-798. [CrossRef]

44. Lin, M.; Li, B.; Li, Q.; Li, S.; Zhang, S. Synergistic effect of metal oxides on the flame retardancy and thermal degradation of novel intumescent flame-retardant thermoplastic polyurethanes. J. Appl. Polym. Sci. 2011, 121, 1951-1960. [CrossRef]

45. Barbot'ko, S.L.; Naumov, I.S.; Vol'nyi, O.S.; Alifanov, E.V. The effect of pigments on the flammability characteristics of a rubber compound based on methylovinylsiloxane rubber. Int. Polym. Sci. 2017, 44, 41-46.

46. Morgan, A. A review of transition metal-based flame retardants: Transition metal oxide/salts, and complexes. In Fire and Polymers V; Wielkie, C.A., Morgan, A., Nelson, G.L., Eds.; American Chemical Society: Washington, DC, USA, 2009; pp. 312-328.

(C) 2020 by the authors. Licensee MDPI, Basel, Switzerland. This article is an open access article distributed under the terms and conditions of the Creative Commons Attribution (CC BY) license (http://creativecommons.org/licenses/by/4.0/). 